\title{
Contribution of DGs in the stability and voltage drop reduction for future MV network in desert regions
}

\author{
Bouafia Abdelkader, Labed Djamel \\ Department of Electrical Engineering, University Frères Mentouri-Constantine1, Algeria
}

\begin{tabular}{l}
\hline Article Info \\
\hline Article history: \\
Received Oct 5, 2019 \\
Revised Nov 9, 2019 \\
Accepted Jan 23, 2020 \\
\hline
\end{tabular}

Keywords:

Ambient temperature

Distributed generation

MV network

Voltage drop

Voltage stability index

\begin{abstract}
Day by day, the integration of decentralized generation in medium voltage networks becomes more important during the last years and even in the near future. This increase causes, at the same time, several negative effects and rarely positive impacts on the stability of the network. Therefore, this work aims at analyzing the impact of ambient temperature on radial distribution network parameters' e.g.: voltage drop and stability voltage level (index). Based on MATLAB program, different analyses of distributed generation (DG) insertion influence's on voltage drop in the radial distribution feeder, as well as the influence of climatic conditions such as ambient temperature on network parameters. The Integration of Photovoltaic DGs in MV networks can play an important role in reducing the global warming effect (in voltage drop, and voltage stability index) especially in radial distribution feeder. Furthermore, it protects network's parameters if its location and power are well selected.
\end{abstract}

This is an open access article under the $\underline{C C B Y-S A}$ license.

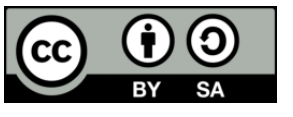

\section{Corresponding Author:}

Abdelkader Bouafia,

Laboratory of Electrical Engineering of Constantine, Department of Electrical Engineering,

University Frères Mentouri -Constantine 1, Campus Ahmed Hamani, Route Ain-El-Bey, Constantine.

Algeria

Email: bouafia.aek@gmail.com

\section{INTRODUCTION}

In the electricity sector the first step in understanding the impacts of climate change is based on knowing the certain terms such as increasing the ambient air temperature [1]. Around the world, environmental pollution has experienced a real acceleration in recent years; this acceleration has several forms such as the increase in heat of the gallop. In a desert region the heat can vary in normal cases between 5 up to $50^{\circ} \mathrm{C}$, and on this basis several systems are installed especially those affected by the ambient temperature such as electrical energy distribution systems. The data bases used by the operators in the tables of facilities are drawn up on the basis of $25^{\circ} \mathrm{C}$ and $50^{\circ} \mathrm{C}$. But this reality will change over time as a result of global warming, for example; the ADRAR region (desert) recorded a maximum temperature on July 9, 2018 which reached $65^{\circ} \mathrm{C}$ [2]. These new records recorded can seriously affect the stability of the electrical power distribution system in general, and the parameters dependent on the particular ambient temperature such as voltage drop.

Therefore, the electrical distribution systems have to be re-studied, and get an overall idea of the increase in ambient temperature impacts on the voltage stability of the electrical system, and the use of DGs as solution which also have impacts on stability. In this context, several studies focused on the integration impacts of the decentralized generation in the distribution networks, these impacts can take several aspects. Some researchers were carried out on DG technology and its impacts on the energy system. These impacts may concern network planning, losses, voltage, energy quality and reliability [3-8]. The large number of DG 
penetration has an influence on voltage disruption, voltage drop in distribution systems particularly with selfdisconnection of loads [9-10]. Therefore, when DGs are integrated, some standards should be respected such as the insertion place as well as the DGs number and its size. The location and technology type of DGs (active and reactive energy injection, active energy injection only, active energy injection and absorbs reactive energy) effects the energy losses [11-16]. Some researches determine the optimal penetration level to $30 \%$ to minimize the DGs intermittent effects such as wind turbines and photovoltaics [17-18]. With the great growth of the installation of the DGs, others focus on algorithms and models that make it possible managing and controlling the distribution system and analyze the loads flow such as active power and reactive communication systems [19-20]. Several studies are done on voltage stability index and its relation to DG type, to rate contribution and to DGs integrated parameters [21-29].

Some studies show the influence of the ambient temperature on the electric system, as the impact study of the increase of ambient temperature and harmonics on the transformers which reduces its life time [30]. Moreover, the impact of the climatic changes (increase of ambient temperature) on energy system infrastructures can reduce the DGs capacity especially in the desert regions as Western United States [31-32]. Other studies show the changes in resistance values of the transmission lines caused by the temperature ambient are non-negligible effects [33]. This paper focuses on the ambient temperature impact on voltage stability of the radial distribution systems (voltage stability index, voltage drop) of electric energy system in the desert regions, as well as the advantage of the insertion of distributed generation. For This, this paper is divided into two main parts; the first consists of concepts and equations that relate the drop and stability of the voltage at ambient temperature. As for the second part it depends on a case study on a 4bus feeder test system and IEEE 33 bus radial distribution system.

\section{PROBLEM FORMULATION}

In this paper, the objective functions of ambient temperature to reconfiguration problem are voltage drop and voltage stability index which are calculated for each case in radial distributed systems.

\subsection{Voltage drop (VD)}

Voltage drops (VD) is the difference between the voltage at the source (or sending end) bus (Vs), which is assumed to be a fixed value, and the voltage at the load (or receiving end) bus (VL), which varies as a function of the load current $\left(l_{\mathrm{L}}\right)$. [34]

\subsection{Factors affecting voltage drop}

One can classify the factors affecting the voltage drop in two categories. The first is dependent to load parameters that are; voltage, current and power factor, the second factor depends on line impedance i.e.; length and resistance. This last is linked directly to the material nature (copper, aluminum ...), to the conductor cross-section and ambient temperature.

\subsection{Voltage drop calculations}

The determination of voltage drop value for lines inferior to $50 \mathrm{~km}$ in medium voltage network (U < $40 \mathrm{kV}$ ) is based on two formulas:

First formula that gives the exact result:

$$
V D=V s+I R \cos (\theta)+I X \sin (\theta)-\left[V s^{2}-(I R \cos (\theta)+I X \sin (\theta))^{2}\right]^{1 / 2}
$$

Where: VD is the voltage drop, I is the line current (A), R is the circuit line resistance $(\Omega), \mathrm{X}$ : is the circuit line reactance $(\Omega)$, and $\theta$ is the load power factor angle (degrees) Vs; source voltage, VL load voltage. The voltage drops VD that is calculated as a line-to-neutral voltage drop (one-way), and the line-to-line voltage drop. And a second approximate formula that nearly gives the same values is:

$$
\begin{aligned}
& V D=I R \cos (\theta)+I X \sin (\theta)=I Z \\
& \mathrm{Z}=R \cos (\theta)+X \sin (\theta)
\end{aligned}
$$

that is calculated for a single-phase system is $2 \mathrm{VD}$; and the tine-to-tine voltage drop that is calculated for a three-phase system is $\sqrt{3} \mathrm{VD}$. So, one can determine the percentage of the voltage drop by the following formula: [35]

$$
V D(\%)=\frac{V D}{V_{S}} * 100
$$




\subsection{Ambient temperature impact on voltage drop}

The change in resistance as a function can be represented by the following formula:

$$
\mathrm{R} 2=\mathrm{R} 1[(\mathrm{k}+\mathrm{T} 2) /(\mathrm{k}+\mathrm{T} 1)]
$$

where:

$\mathrm{R} 1$ is a conductor resistance in ohms $(\Omega)$ at temperature T1 in degrees Celsius $\left({ }^{\circ} \mathrm{C}\right)$

$\mathrm{R} 2$ is a conductor resistance in ohms $(\Omega)$ at temperaturesT2 in degrees Celsius $\left({ }^{\circ} \mathrm{C}\right)$

and $\mathrm{k}$ is the resistivity temperature coefficient at $0^{\circ} \mathrm{C}$ for the conductor; $\mathrm{k}=234.5$ for copper, Aluminum 228 , lead 230, steal 202. [35]

For $\mathrm{T}=\mathrm{T}_{1}$ et $\mathrm{R}=\mathrm{R}_{1}$

$\mathrm{VD} 1=\mathrm{I} *\left[\mathrm{R}_{1} * \cos (\theta)+\mathrm{X}_{1} * \sin (\theta)\right]$

and for $\mathrm{T}=\mathrm{T}_{2}, \mathrm{R}=\mathrm{R}_{2}$

$$
\mathrm{R}_{2}=\mathrm{R}_{1}\left[\left(\mathrm{k}+\mathrm{T}_{2}\right) /\left(\mathrm{k}+\mathrm{T}_{1}\right)\right]
$$

So

$$
\mathrm{VD}_{2}=\mathrm{I}\left(\mathrm{R}_{2} * \cos \theta+\mathrm{X}_{1} * \sin \theta\right)
$$

$\mathrm{X}_{1}$ is independent of ambient temperature. Therefore, the (7) becomes;

$$
\mathrm{VD}_{2}=\mathrm{I}\left[\mathrm{R}_{1}\left[\left(\mathrm{k}+\mathrm{T}_{2}\right) /\left(\mathrm{k}+\mathrm{T}_{1}\right)\right] * \cos \theta+\mathrm{X}_{1} * \sin \theta\right]
$$

and from (4) and (7) the percent voltage drop becomes

$$
\mathrm{VD}_{2} \%=\mathrm{I}\left[\left[\mathrm{R}_{1}\left(\frac{\mathrm{k}+\mathrm{T}_{2}}{\mathrm{k}+\mathrm{T}_{1}}\right)\right] * \cos \theta+\mathrm{X}_{1} * \sin \theta\right] * 100 / \mathrm{V}_{\mathrm{S}}
$$

voltage drop equal $\sqrt{3} \mathrm{VD}$ for three phase system

So, the percent voltage drop for three phase system formula becomes;

$$
\mathrm{VD}_{2} \%=\sqrt{3} \mathrm{I}\left[\left[\mathrm{R}_{1}\left(\frac{\mathrm{k}+\mathrm{T}_{2}}{\mathrm{k}+\mathrm{T}_{1}}\right)\right] * \cos \theta+\mathrm{X}_{1} * \sin \theta\right] * 100 / \mathrm{V}_{\mathrm{S}}
$$

the (8) means that there is a relation between the ambient temperature and voltage drop variation.

\subsection{Voltage stability index (VSI)}

Voltage stability is the ability of a power system to maintain steady acceptable voltages at all buses in the system under normal operating conditions and after being subjected to a disturbance, a system enters a state of voltage instability when a disturbance, increase in load demand, or change in system condition causes a progressive and uncontrollable drop in voltage [36]-[38].

\subsection{Voltage stability index calculations}

Voltage stability index can determined in favor of this formula:

$$
\operatorname{VSI}(\mathrm{r})=2 \mathrm{~V}_{\mathrm{S}}^{2} \mathrm{~V}_{\mathrm{r}}^{2}-\mathrm{V}_{\mathrm{r}}^{4}-2 \mathrm{~V}_{\mathrm{r}}^{2}(\mathrm{PR}+\mathrm{QX})-|\mathrm{Z}|^{2}\left(\mathrm{P}^{2}+\mathrm{Q}^{2}\right)
$$

when s is source, $r$ is loads and $\mathrm{R}, \mathrm{X}, \mathrm{Z})$ impedance of line, $\mathrm{P}$ and $\mathrm{Q}$ is charges [39]. In reality there are other formula to calculate

\subsection{Ambient temperature impact's on voltage stability index}

The formula shows that voltage stability level has a big relation with the line impedance, voltage buses, and load power. The impedance value increases with increase of its resistance as the ambient temperature increases. This affect the voltage stability index in the different buses of the power system (see formula 5) So, formula 10 becomes:

$$
\operatorname{VSI}(\mathrm{r})=2 \mathrm{~V}_{\mathrm{S}}^{2} \mathrm{~V}_{\mathrm{r}}^{2}-\mathrm{V}_{\mathrm{r}}^{4}-2 \mathrm{~V}_{\mathrm{r}}^{2}(\mathrm{P} * \mathrm{R} 1[(\mathrm{k}+\mathrm{T} 2) /(\mathrm{k}+\mathrm{T} 1)]+\mathrm{QX})-\left|\mathrm{Z}^{\prime}\right|^{2}\left(\mathrm{P}^{2}+\mathrm{Q}^{2}\right)
$$




\section{METHODOLOGY AND SIMULATION}

We will devise this part of simulation in tow devises, the first talk about the impact of ambient temperate in voltage drop value for case to IEEE 4-Bus Test Feeder, and who can limit its effects as shown in Table 1. The second simulation devise of take IEEE 33-Bus Test Feeder radial distribution system like example to effects of insertion of DGs on voltage stability index value, and selection of the good conditions to support voltage stability.

Table 1. Parameters of IEEE 4 bus test feeder elements

\begin{tabular}{lllll}
\hline Source & Line $1(\mathrm{~L} 1)$ & Cable $1(\mathrm{~L} 2)$ & Transformer & Load \\
\hline $\mathrm{S}_{\mathrm{S}}=100 \mathrm{MVA}$ & $\mathrm{R}_{\mathrm{Cl}}=0.09 \Omega / \mathrm{km}$ & $\mathrm{R}_{\mathrm{C} 2}=0.09 \Omega / \mathrm{km}$ & $12,47 / 4,16 \mathrm{KV}$ & $\mathrm{V}_{\mathrm{L}}=4,16 \mathrm{kV}$ \\
$\mathrm{Vs}=12,47 \mathrm{kV}$ & $\mathrm{X}_{\mathrm{Cl}}=0.52 \Omega / \mathrm{km}$ & $\mathrm{X}_{\mathrm{C} 2}=0.52 \Omega / \mathrm{km}$ & $\mathrm{R}_{\mathrm{Cl}}=0.132 \Omega$ & $\mathrm{I}_{\mathrm{L}}=1200 \mathrm{~A}$ \\
$\mathrm{R}_{\mathrm{S}}=0.12 \Omega$ & $\mathrm{Imax}=2000 \mathrm{~A}$ & $\mathrm{Imax}=2000 \mathrm{~A}$ & $\mathrm{X}_{\mathrm{Cl}}=0.62 \Omega$ & $\mathrm{X} / \mathrm{R}=15$ \\
$\mathrm{X}_{\mathrm{S}}=0.48 \Omega$ & $\mathrm{L}_{1}=3 \mathrm{~km}$ & $\mathrm{~L} 2=0,672 \mathrm{~km}$ & & $\mathrm{Pf}=90 \%$ \\
\hline
\end{tabular}

\subsection{Fist case: IEEE 4-bus test feeder}

To carry out a simulation of the distribution network during hot days, the 8 th of June temperature model will be applied (Figure 1) on the model IEEE 4 Node test feeder (Figure 2).

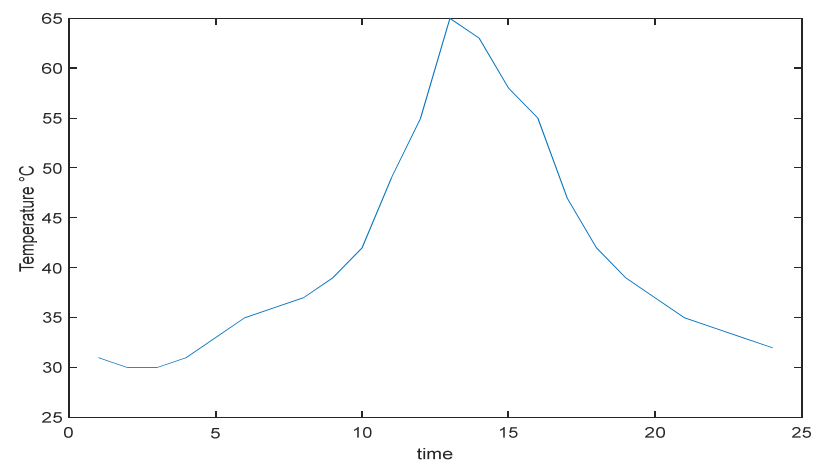

Figure 1. Temperature in ADRAR region for the $9^{\text {th }}$ of Juley 2018

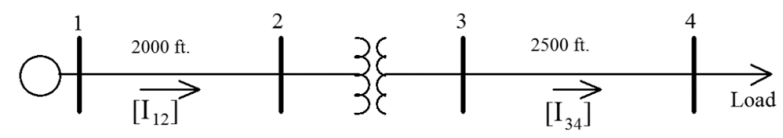

Figure 2. IEEE 4-bus test feeder

By using MATLAB program, the variations of voltage drop in the 4 buses during 24 hours can be determined (see Figure 3).

This figure shows that the ambient temperature variance influences the impedance of the overhead lines and finally over the entire distribution network. But there are two cases; a positive case that is attached to the ambient temperature decrease, and a second considered negative that is the case of the ambient temperature increase, it is considered by the growth of the percentage (\%) of the voltage drop. 

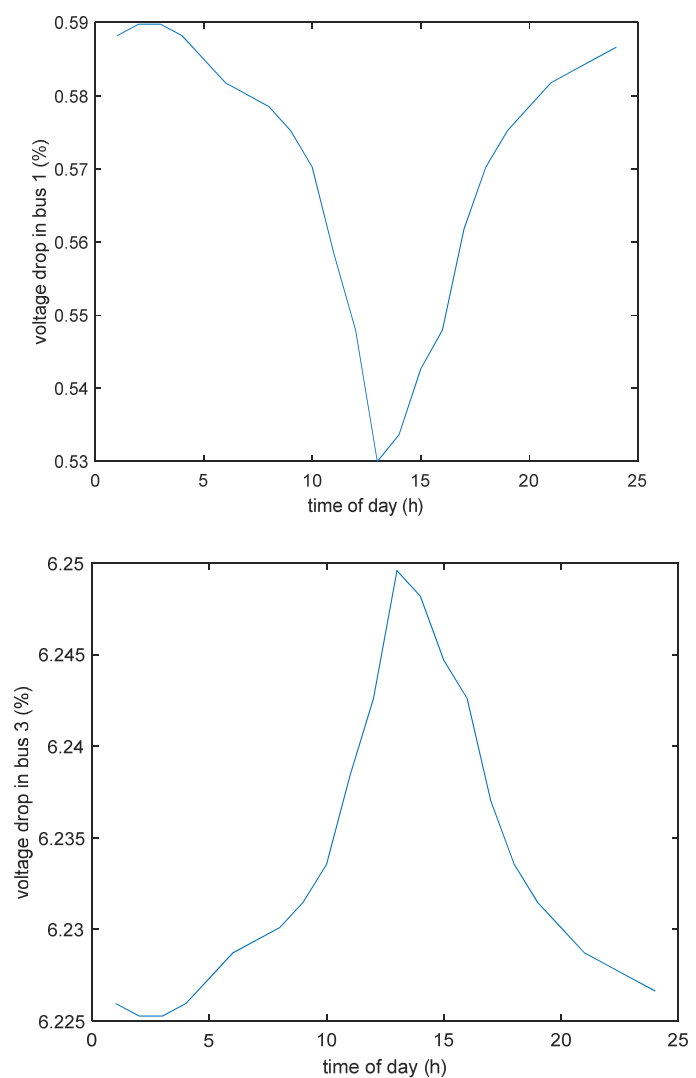
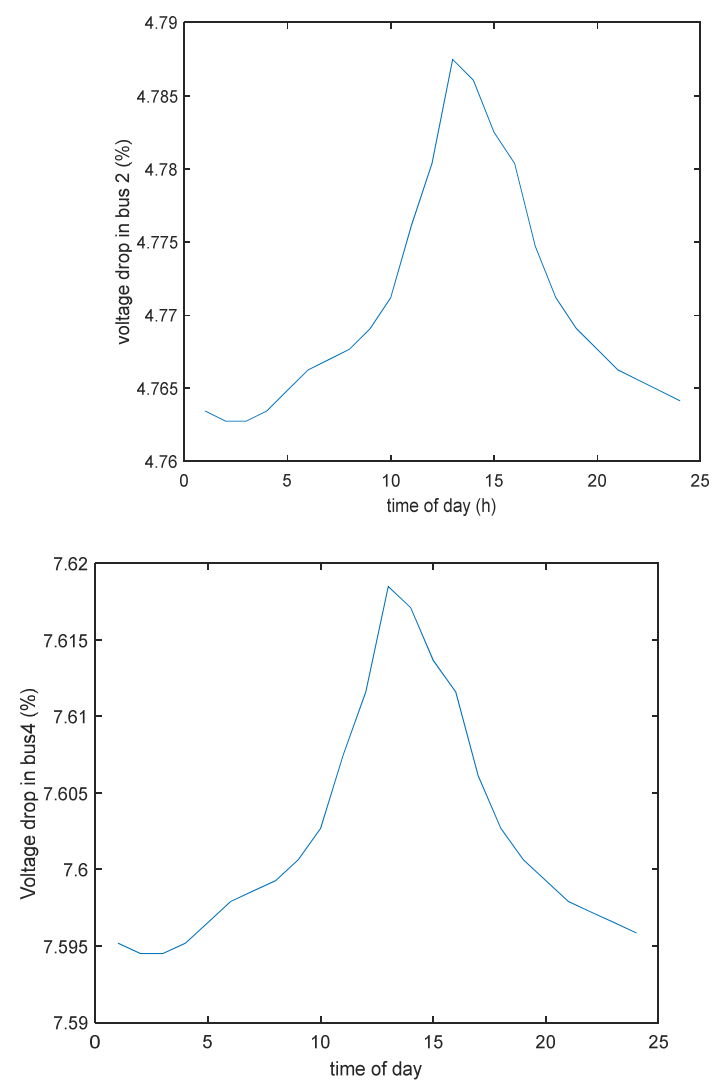

Figure 3. rate of voltage drop change in bus 1,2,3,4 during $24 \mathrm{~h}$

\subsection{Advantage of DG in voltage drop reduction}

In order to see the nature and the intensity of the temperature influence on voltage drop calculations and especially in the future medium voltage networks where connected DGs may be found. Based on that, the following application in two different seasons is taken. The first one in winter where the change in temperature from $-5{ }^{\circ} \mathrm{C}$ up to $20^{\circ} \mathrm{C}$, the second one in summer that varies from $20^{\circ} \mathrm{C}$ up to $60^{\circ} \mathrm{C}$, and sometimes exceeds $65^{\circ} \mathrm{C}$ in some Sahara regions and sub-of the Sahara. Consequently, the study interval should be taken from $-5^{\circ} \mathrm{C}$ up to $70^{\circ} \mathrm{C}$. In the first case, an application is carried out on a simple network that contains a source, a transmission line MT and a load, the voltage drop for the bus 2 is therefore calculated (see Figure 4 (a)). In the second case, a DG source is connected to see how the changes made influence (see Figure 4 (b)). The DG contributes in the load supply with 50\%. And Table below presents data of the different elements of the network studied. Figure 5 determines the ambient temperature impact on the voltage drop value in bus 2 . The calculations made by technicians are often made for an ambient temperature of $25^{\circ} \mathrm{C}$ where $\mathrm{VD}=3.1 \%$. It can be noted that the temperature can exceed this threshold and the calculations made becomes very far from reality. The insertion of a DG source at the proximity of the bus 2 plays a very positive role in the backup of the VD in these standards (VD is $~ 7 \%$ for MV [40]). 


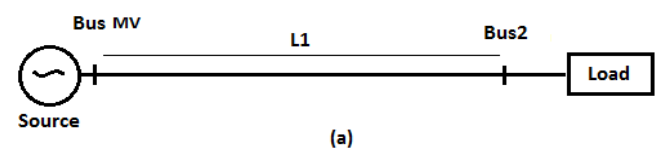

(a)

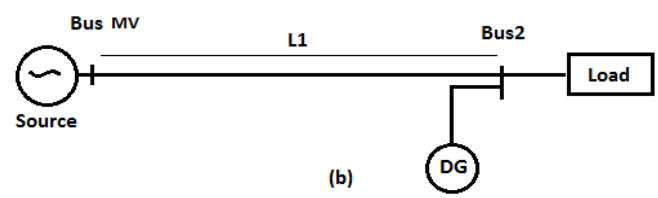

Figure 4. Simple medium voltage network with and without DG connection

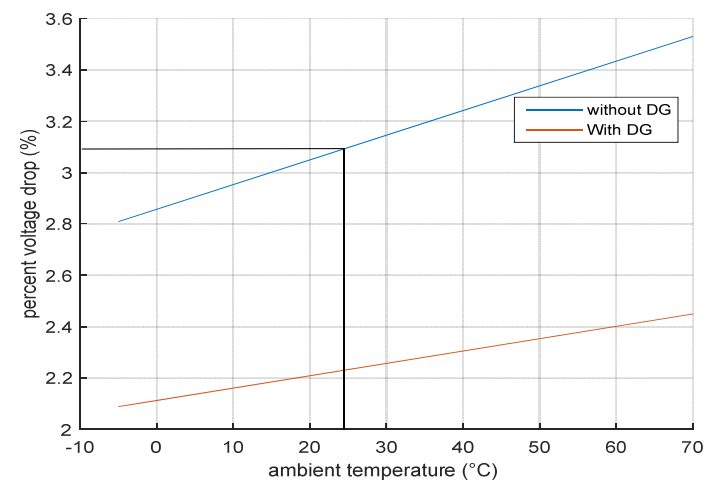

Figure 5. Voltage drop change in bus 2 under ambient temperature influence with and without DG insertion

Table 2. Numerical data for simple circuit like figure 2

\begin{tabular}{llll}
\hline Source & $\mathrm{DG}$ & Line $1(\mathrm{~L} 1)$ & Load \\
\hline $\mathrm{S}_{\mathrm{S}}=120 \mathrm{MVA}$ & $\mathrm{S}_{\mathrm{DG}}=10 \mathrm{MVA}$ & $\mathrm{R}_{\mathrm{L} 1}=1,65 \Omega / \mathrm{km}$ & $\mathrm{V}_{\mathrm{L}}=11,5 \mathrm{kV}$ \\
$\mathrm{Vs}=30 \mathrm{kV}$ & $\mathrm{V}_{\mathrm{DG}}=30 \mathrm{kV}$ & $\mathrm{X}_{\mathrm{L} 1}=1,22 \Omega / \mathrm{km}$ & $\mathrm{I}_{\mathrm{L}}=105,7 \mathrm{~A}$ \\
$\mathrm{R}_{\mathrm{S}}=0.12 \Omega$ & $\mathrm{R}_{\mathrm{DG}}=0,80 \Omega$ & $\mathrm{Imax}_{2}=2000 \mathrm{~A}$ & $\mathrm{X} / \mathrm{R}=15$ \\
$\mathrm{X}_{\mathrm{S}}=0.48 \Omega$ & $\mathrm{X}_{\mathrm{DG}}=0,32 \Omega$ & $\mathrm{L}_{\mathrm{l}}=3 \mathrm{~km}$ & $\mathrm{Pf}=0,95$ \\
\hline
\end{tabular}

\subsection{Second case: IEEE 33-bus radial distribution}

In order to confirm the impact of DG insertion and its location on the voltage stability index (level) under ambient temperature, an MV 33 radial bus distribution network (Figure 6) is used. This distribution system contains 33 bus (nodes) and a 3.715 MVA, 2.3 MVAR, 12.47kV power source. For further data see the Appendix (A \& B).

The measured voltage in the different bus bars under ambient temperatures is: $-5^{\circ} \mathrm{C}, 25^{\circ} \mathrm{C}$ and $65^{\circ} \mathrm{C}$ respectively. These temperatures represent the two ends of $\mathrm{T} 2$ and $25{ }^{\circ} \mathrm{C}$ represents $\mathrm{T} 1$. The results obtained are presented in Figure 7. The figure shows the degradation of the voltage level along the line, especially in buses 18 and 33 under the effect of the ambient temperature increase. This also causes a decrease in the level of voltage stability index (see Figure 8). The future MV distribution networks are networks with high possibility of the DGs insertion in one or more points. This type of networks suffers from climate heating but has the advantage of being in areas of very high annual average solar radiation, so it is very advantageous to install DGs of photovoltaic PV types. In fact, it has firstly been dealt with this type of problem by trying integrating a PV type DG with a $0.5 \mathrm{MW}$ active power in different IEEE 33 bus bars radial distribution system, the results obtained are shown in Figure 9. The tests indicate that the two sites that are really improving are inserts 18 and 33.

Int J Pow Elec \& Dri Syst, Vol. 11, No. 2, June 2020 : 977 - 987 


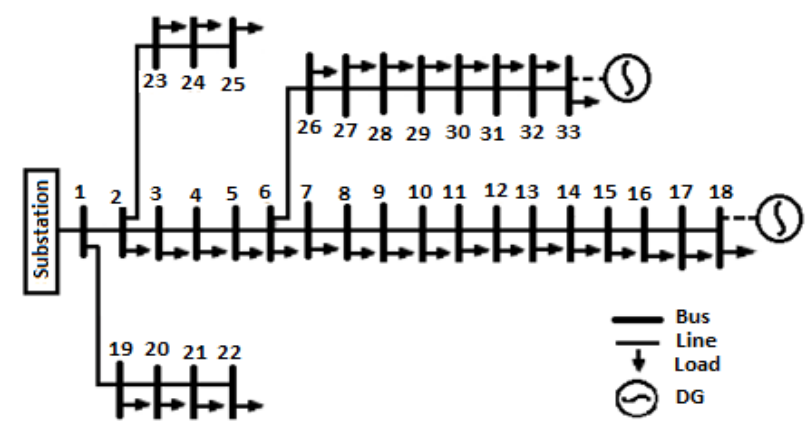

Figure 6. Single line diagram of IEEE 33-bus radial distribution

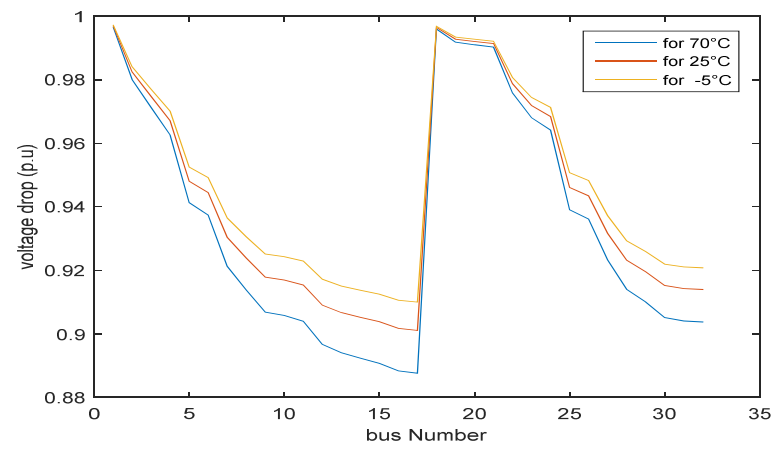

Figure 7. Voltage drop in differences buses for $-5,25$, and $70^{\circ} \mathrm{C}$ respectively

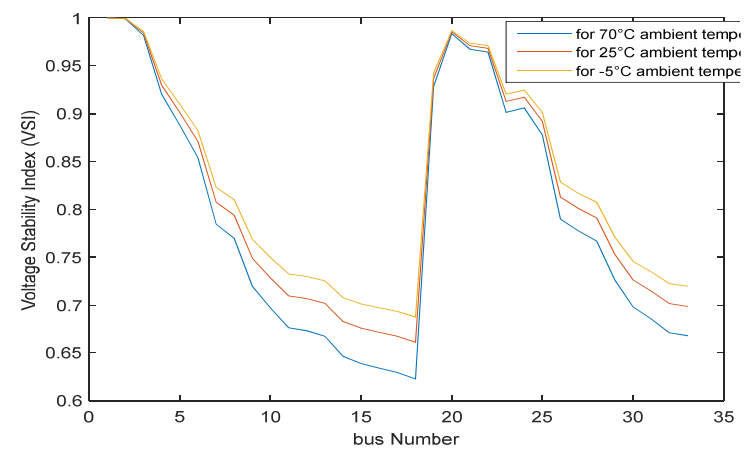

Figure 8. Voltage stability index in buses for different ambient temperatures

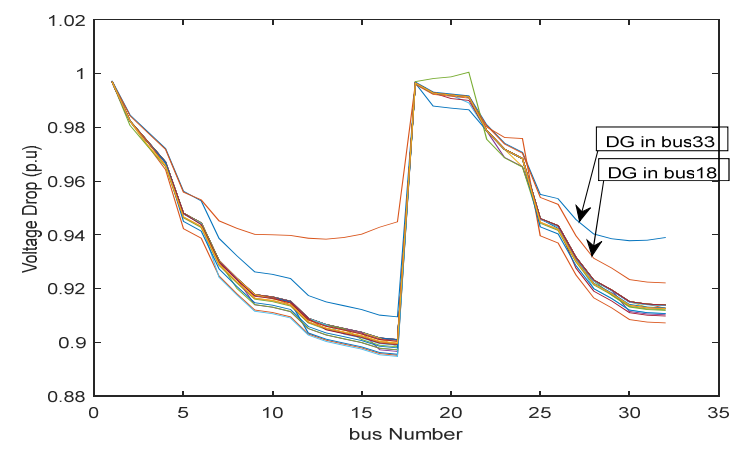

Figure 9. Result to insertion of DG-PV in different buses 


\subsection{DG advantage in voltage stability}

In order to understand the impact of DG insertion or in a MV distribution system, the previous example in the two main points which give good performance in reducing the voltage drop will be used. Four photovoltaic type DGs with different sizes were chosen, see Table 3. These DGs supposed to generate active power only.

Table 3. Distributed generation type and parametrers

\begin{tabular}{lll}
\hline G & Active Power (MVA) & Reactive Power (MVAR) \\
\hline DG1-PV & 0.5 & - \\
DG2-PV & 1.0 & - \\
DG3-PV & 2.0 & - \\
DG4-PV & 4.0 & - \\
\hline
\end{tabular}

\section{RESULTS AND DISCUSSION}

Thirteen (13) possible scenarios of the DGs insertion in IEEE 33-bus radial distribution see table 4. At the beginning the minimum and the maximum of the voltage stability index (SVI) for two different ambient temperatures $25^{\circ} \mathrm{C}$ and $70{ }^{\circ} \mathrm{C}$ is measured, then the divergence min-max (SVI) for each scenario will be calculated. The results obtained are shown in Figure 10.

Three categories of scenarios can be distinguished; better, average and bad. The 10 and 11 scenarios are classified as best category that are related to the insertion of two small DGs $(0.5 \& 1 \mathrm{MW})$ in the bus 18 and 33, the max of this category does not exceed 1 (SVI $\leq 1$ stability), and the divergence min-max is minimum as well as the impact of the ambient temperature appeared almost zero. for the average category one can classify the scenarios 2,3,4 and 5 which are related to the insertion of a single small DG either in the buses 18 or 33, the max of SVI and almost 1, and the divergence Min-Max is under the initial value (without DG), the impact of the ambient temperature is minimum. concerning the bad category it is found the scenarios related to the insertion of one to the two DGs of large sizes ( 2 or $4 \mathrm{MW}$ ), which are the scenarios $(6,7,8,9,12$ and 13), the max usually exceeds 1 (SVI $\geq 1$ instability) and the divergence MinMax is greater than the initial value, and the impact of the ambient temperature is remarkable. From these results it can be noted that the insertion of the small DGs at the end of the branches plays a significant role in the stability of the distribution networks and limits the impact of the ambient temperature on the installation.

Table 4. Presents min and max of Stability voltage index for differencts scenarios

\begin{tabular}{lllllll}
\hline Scenario & DG used & Position & Min SVI for $25^{\circ} \mathrm{C}$ & $\begin{array}{l}\text { Min SVI } \\
\text { for } 70^{\circ} \mathrm{C}\end{array}$ & $\begin{array}{l}\text { Max SVI } \\
\text { for } 25^{\circ} \mathrm{C}\end{array}$ & $\begin{array}{l}\text { Max SVI } \\
\text { for } 70^{\circ} \mathrm{C}\end{array}$ \\
\hline Scenario 1 & Without & - & 0,66116286 & 0,62277933 & 1 & 1 \\
Scenario 2 & DG1-PV & bus 18 & 0,72400454 & 0,70386996 & 1 & 1 \\
Scenario 3 & DG1-PV & bus 33 & 0,68629247 & 0,65581334 & 1 & 1 \\
Scenario 4 & DG2-PV & bus 18 & 0,74888752 & 0,72897958 & 1 & 1 \\
Scenario 5 & DG2-PV & bus 33 & 0,74888752 & 0,68456904 & 1 & 1 \\
Scenario 6 & DG3-PV & bus 18 & 0,79633411 & 0,78088314 & 1,26719789 & 1,30687082 \\
Scenario 7 & DG3-PV & bus 33 & 0,76190067 & 0,74142979 & 1,0306693 & 1,05094967 \\
Scenario 8 & DG4-PV & bus 18 & 0,87798095 & 0,87212255 & 2,00982316 & 2,16617314 \\
Scenario 9 & DG4-PV & bus 33 & 0,85830433 & 0,84886693 & 1,41000027 & 1,48224003 \\
Scenario 10 & Tow DG1-PV & bus18 \& 33 & 0,80079868 & 0,78886449 & 1 & 1 \\
Scenario11 & Tow DG2-PV & bus18 \& 33 & 0,89593788 & 0,89625162 & 1,00037338 & 1,01569951 \\
Scenario12 & Tow DG3-PV & bus18 \& 33 & 0,94841805 & 0,94400568 & 1,40370693 & 1,47522629 \\
Scenario13 & Tow DG4-PV & bus18 \& 33 & 0,96031167 & 0,95452289 & 2,37014846 & 2,6318921 \\
\hline
\end{tabular}

Int J Pow Elec \& Dri Syst, Vol. 11, No. 2, June 2020 : 977 - 987 


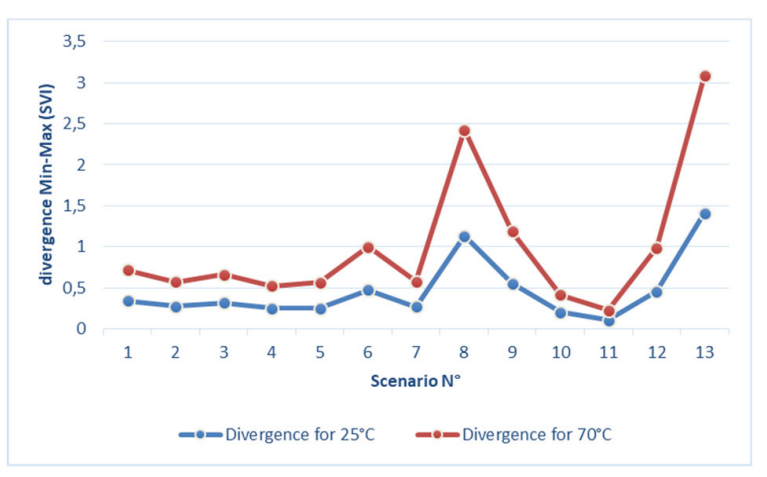

Figure 10. divergence min-max of Stability voltage index to differencts scenarios for $25^{\circ} \mathrm{C}$ and $70^{\circ} \mathrm{C}$

\section{CONCLUSION}

The electric energy distribution system is usually exposed to external impacts such as the ambient temperature that affects the internal stability parameters of the electric system that is usually voltage. For future electric distribution networks, the climate change effects should be taken into consideration during the phase of installation and especially for the calculations of the transmission lines impedances by keeping the ambient temperature superior or equal to $75^{\circ} \mathrm{C}$. The insertion of the DGs remains a good means to fight against the impact of these temperature peaks that often touches the Sahara zones. The DGs insertion in a radial distribution network and its impact on voltage drop and on voltage drop indices under the effect of the difficult climatic conditions (extreme hot temperature zones) has been studied in this paper.

It has been shown that DGs can play a very important role in the improvement of the voltage stability index, as well as limitation of the voltage drop for future electric distribution networks, selection of the size, number and the insertion points of the DGs that well reduces of voltage drop and give a good stability. The impact of the ambient temperature on voltage drop (VD) and on voltage stability indication (VSI) that appears minimal in the different chosen scenarios will become more important in the most complex electric distribution networks and especially during peak days. According to the study, the optimal position where the DGs should be inserted in the radial distribution networks is at the ends of the branches as the 33 buses case been studied. The latter deals with the insertion of two photovoltaic type DGs with medium or small dimensions. This has shown a good efficiency in terms of stability for radial distribution network and minimized considerably the increase of the ambient temperature impact.

\section{REFERENCE}

[1] Shankar N C, Frank A F," Impact of climate change on electricity systems and markets-A review of models and forecasts," Elsevier. Sustainable Energy Technologies and Assessments, vol. 5, no. 2014, pp. 62-74C.

[2] La canicule persiste dans 5 wilayas du sud. Accessed on: September 10, 2019. [Online]. available: http://www.radioalgerie.dz/news/fr/article/20180709/145893.html.

[3] Ayong H, Ismail Y, Trias F, Pontia W, Kho H, Khwee, J," Optimum Renewable Fraction for Grid-connected Photovoltaic in Office Building Energy Systems," International Journal of Power Electronics and Drive System (IJPEDS), vol. 9, no. 4, pp. 1866-1874, 2018

[4] Méndez V.H, Rivier J, de laFuente J I, Gómez T, Arceluz J, Marín J, Madurga A,” Impact of distributed generation on distribution investment deferral," International Journal of Electrical Power \& Energy Systems. Vol 28, no. 4, pp 244-252, 2006.

[5] Mahmud M A, Hossain M J, Pota H R," Analysis of Voltage Rise Effect on Distribution Network with Distributed Generation," IFAC Proceedings Volumes. Vol 44, No. 1, pp. 14796-14801, 2011.

[6] Adefarati T, Bansal R.C," Integration of renewable distributed generators into the distribution system: a review," IET Renewable Power Generation. Vol. 10, No. 7, pp. 873 - 884, 2016.

[7] Bignucolo F, Caldon R, Prandoni V, "Radial MV networks voltage regulation with distribution management system coordinated controller," Electric Power Systems Research. Vol 78, no. 4, pp. 634-645, 2008.

[8] Labed I, Labed D, Mansour Z, Fetissi S," Influence of the wind farm integration on load flow and voltage in electrical power system, ”International Journal of Hydrogen Energy, Vol 41, no. 2016, pp. 12603-12617.

[9] Guan F.H, Zhao D.M, Zhang X., Shan B.T, Liu Z, "Research on distributed generation technologies and its impacts on power system," International Conference on Sustainable Power Generation and Supply. Nanjing, China.2009

[10] Koji Y, Yoshihiro K," Influence of voltage sags on the power system with high penetration of photovoltaic power generation," IEEE Power and Energy Society General Meeting. 2012.

[11] Arash A, Thomas W ,Saeed L," The Impacts of Distributed Energy Sources on Distribution Network Reconfiguration," IEEE Transactions on Energy Conversion, vol. 31, no. 2, pp. 606 - 613, 2016 
[12] Niemi R., Lun PD, "Decentralized electricity system sizing and placement in distribution networks," Journal of Applied Energy, “vol. 87, no. 6, pp 1865-1869, 2010.

[13] Murty V.V.S.N. Ashwani K, “ Optimal placement of DG in radial distribution systems based on new vol.tage stability index under load growth," International Journal of Electrical Power \& Energy Systems, vol. 69, pp 246256, 2015.

[14] Afzalan E, Taghikhani M A, Sedighizadeh M," Optimal Placement and Sizing of DG in Radial Distribution Networks Using SFLA,” International Journal of Energy Engineering, vol. 2, no. 3, pp. 73-77, 2012.

[15] Hedayati H, Nabaviniaki S A, Akbarimajd A, "A Method for Placement of DG Units in Distribution Networks," IEEE Transactions on Power Delivery, vol. 23, no. 3, pp: 1620 - 1628, 2008.

[16] Abu-Mouti F S, El-Hawary M E," Heuristic curve-fitted technique for distributed generation optimization in radial distribution feeder systems," IET Generation, Transmission \& Distribution. vol. 5, no. 2, pp.172-180, 2011.

[17] Angelim J H, Affonso C M," Impact of distributed generation technology and location on power system vol.tage stability," IEEE Latin America Transactions, vol.. 14, no. 4, pp.1758 - 1765, 2016.

[18] Duong M Q, Tran N T N, Sava G N ; Scripcariu M, " The impacts of distributed generation penetration into the power system," International Conference on Electromechanical and Power Systems (SIELMEN) Iasi. Romania. 2017.

[19] Wang L, Yan R, and Saha T K," Vol.tage Management for Large Scale PV Integration into Weak Distribution Systems," IEEE Transactions on Smart Grid, vol. 9, no. 5, pp. 4128-4139, 2018.

[20] Al Abri R S, El-Saadany E F, Atwa Y M,"Optimal Placement and Sizing Method to Improve the Vol.tage Stability Margin in a Distribution System Using Distributed Generation", IEEE Transactions on Power Systems, vol. 28, no. 1, pp.326-334,2013

[21] Khushalani S, Solanki J M., Schulz N N." Development of Three-Phase Unbalanced Power Flow Using PV and PQ Models for Distributed Generation and Study of the Impact of DG Models," IEEE Transactions on Power Systems, vol. 22, no. 3, pp. 1019-1025. 2007.

[22] Delfino F, Procopio R, Rossi M, Ronda G," Integration of large-size photovol.taic systems into the distribution grids: a p-q chart approach to assess reactive support capability," IET Renewable Power Generation Vol.. 4, Issue: 4 , July 2010.

[23] Zabaiou T, Dessaint L A, Kamwa I," Preventive control approach for vol.tage stability improvement using vol.tage stability constrained optimal power flow based on static line vol.tage stability indices," in IET Generation, Transmission \& Distribution, vol. 8, no. 5, pp. 924 - 934, May 2014.

[24] Refaat S S, Abu-Rub H, Sanfilippo A P,” Dynamic Vol.tage Stability Impact of Large-Scale Photovol.taic System on Electric Power Grids," 5th IET International Conference on Renewable Power Generation, 21-23 Sept. 2016. London, UK.

[25] Labed I, Labed D, Extreme learning machine-based alleviation for overloaded power system, IET Generation, Transmission \& Distribution, vol. 13, no. 22, pp 5058 - 5070, 2019.

[26] Arash A, Thomas W ,Saeed L,'The Impacts of Distributed Energy Sources on Distribution Network Reconfiguration, " IEEE Transactions on Energy Conversion, vol. 31, no. 2, pp. 606 - 613, 2016

[27] Castillo F, Aguila A, González J," Analysis of Stability of Tension and Losses of Electric Power in Distribution Networks with Distributed Generation," IEEE Latin America Transactions, vol. 14, no. 11, Nov. 2016.

[28] do Prado C C, Bernardon D P, Pires C L, Martins C C , Lucchese F C," Analysis of distributed generation impact on the vol.tage stability margin," 51st International Universities Power Engineering Conference (UPEC). Coimbra, Portugal. 2016.

[29] Sekhane H, Labed D. Identification of the Weakest Buses to Facilitate the Search for Optimal Placement of Var Sources Using “Kessel and Glavitch” Index. Journal of Electrical Engineering \& Technology, vol; 14, no. 2019, pp $1473-1483$

[30] Kamel M, Karrar A A, Eltom A H,'Development and Application of a New Vol.tage Stability Index for On-Line Monitoring and Shedding," IEEE Transactions on Power Systems, vol. 33, no. 2, pp 1231-1241, 2018.

[31] Sadati S B, Yazdani-Asrami M, Taghipour M, "Effects of Harmonic Current Content and Ambient Temperature on Load Ability and Life Time of Distribution Transformers," International Review of Electrical Engineering (I.R.E.E.), vol. 5, no. 4. July-August 2010.

[32] Matthew D. B, Mikhail V C, "Impacts of climate change on electric power supply in the Western United States." Natural climate change. 2015.

[33] Sathaye J A, Dale L L, Larsen P H, Fitts G A, Koy K, Lewis S M, deLucena A F P, "Estimating impacts of warming temperatures on California's electricity system," Elsevier, Global Environmental Change, vol. 23, no. 2013, pp. 499-511.

[34] Marija B, Goran A, "Transmission Line Conductor Temperature Impact on State Estimation Accuracym," IEEE Lausanne Power Tech Conference. 1-5 July 2007. Lausanne, Switzerland.

[35] Das K. electrical power system for industrials plants. Jaico Publiching House. 2008.

[36] Kundur P. Power System Stability and Control. (part 1), McGraw-Hill Professional. 1994.

[37] Eminoglu U, Hocaoglu M.H. A Vol.tage Stability Index for Radial Distribution Networks. 42nd International Universities Power Engineering Conference. Brighton, UK. 2007.

[38] Arvind R, Nur Fadilah A, Zuhaila Mat Y, Nur Ashida S," Investigation of distributed generation unit's placement and sizing based on vol.tage stability condition indicator (VSCI)," International Journal of Power Electronics and Drive System (IJPEDS), vol. 10, no. 3, pp. 1317-1323, 2019. 
[39] Labed D. Production Decentralisee Et Couplage AU Reseau. Ph.D Thesis. Department of electrical engineering, university frères Mentouri -Constantine1, Algeria. 2008. Accessed on: November 5, 2019. [Online]. Available: https://bu.umc.edu.dz/theses/electrotec/LAB5238.pdf

[40] Didier F. Basic selection of MV public distribution networks. technic Notebook, Schneider electric. ECT ${ }^{\circ} 203$. issue May 2001.

Appendix:

Table A. Load data of the IEEE-33 radial distribution system

\begin{tabular}{|c|c|c|c|}
\hline Load & $\begin{array}{c}\text { Location } \\
\text { (bus) }\end{array}$ & $\begin{array}{l}\text { Real Load } \\
(\mathrm{kW})\end{array}$ & Reactive Load (kVAR) \\
\hline Load2 & 2 & 100 & 60 \\
\hline Load3 & 3 & 90 & 40 \\
\hline Load4 & 4 & 120 & 80 \\
\hline Load5 & 5 & 60 & 30 \\
\hline Load6 & 6 & 60 & 20 \\
\hline Load7 & 7 & 200 & 100 \\
\hline Load8 & 8 & 200 & 100 \\
\hline Load9 & 9 & 60 & 20 \\
\hline Load10 & 10 & 60 & 20 \\
\hline Load11 & 11 & 45 & 30 \\
\hline Load12 & 12 & 60 & 35 \\
\hline Load 13 & 13 & 60 & 35 \\
\hline Load14 & 14 & 120 & 80 \\
\hline Load15 & 15 & 60 & 10 \\
\hline Load 16 & 16 & 60 & 20 \\
\hline Load 17 & 17 & 60 & 20 \\
\hline Load 18 & 18 & 90 & 40 \\
\hline Load19 & 19 & 90 & 40 \\
\hline Load20 & 20 & 90 & 40 \\
\hline Load 21 & 21 & 90 & 40 \\
\hline Load 22 & 22 & 90 & 40 \\
\hline Load 23 & 23 & 90 & 50 \\
\hline Load 24 & 24 & 420 & 200 \\
\hline Load 25 & 25 & 420 & 200 \\
\hline Load 26 & 26 & 60 & 25 \\
\hline Load 27 & 27 & 60 & 25 \\
\hline Load 28 & 28 & 60 & 20 \\
\hline Load29 & 29 & 120 & 70 \\
\hline Load30 & 30 & 200 & 600 \\
\hline Load31 & 31 & 150 & 70 \\
\hline Load32 & 32 & 210 & 100 \\
\hline Load33 & 33 & 60 & 40 \\
\hline
\end{tabular}

Table B. Line data of the IEEE 33-bus radial distribution system

\begin{tabular}{|c|c|c|c|c|c|}
\hline Branch & $\begin{array}{l}\text { From } \\
\text { bus }\end{array}$ & $\begin{array}{l}\text { To } \\
\text { bus }\end{array}$ & $\begin{array}{l}\text { Length } \\
(\mathrm{km})\end{array}$ & $\begin{array}{l}\text { Impedance } \\
\text { Resistance }\end{array}$ & Reactance \\
\hline 1 & 1 & 2 & 1 & 0.0922 & 0.0470 \\
\hline 2 & 2 & 3 & 1 & 0.4930 & 0.2511 \\
\hline 3 & 3 & 4 & 1 & 0.3660 & 0.1864 \\
\hline 4 & 4 & 5 & 1 & 0.3811 & 0.1941 \\
\hline 5 & 5 & 6 & 1 & 0.8190 & 0.7070 \\
\hline 6 & 6 & 7 & 1 & 0.1872 & 0.6188 \\
\hline 7 & 7 & 8 & 1 & 1.7114 & 1.2351 \\
\hline 8 & 8 & 9 & 1 & 1.0300 & 0.7400 \\
\hline 9 & 9 & 10 & 1 & 1.0440 & 0.7400 \\
\hline 10 & 10 & 11 & 1 & 0.1966 & 0.0650 \\
\hline 11 & 11 & 12 & 1 & 0.3744 & 0.1238 \\
\hline 12 & 12 & 13 & 1 & 1.4680 & 1.1550 \\
\hline 13 & 13 & 14 & 1 & 0.5416 & 0.7129 \\
\hline 14 & 14 & 15 & 1 & 0.5910 & 0.5260 \\
\hline 15 & 15 & 16 & 1 & 0.7463 & 0.5450 \\
\hline 16 & 16 & 17 & 1 & 1.2890 & 1.7210 \\
\hline 17 & 17 & 18 & 1 & 0.7320 & 0.5740 \\
\hline 18 & 2 & 19 & 1 & 0.1640 & 0.1565 \\
\hline 19 & 19 & 20 & 1 & 1.5042 & 1.3554 \\
\hline 20 & 20 & 21 & 1 & 0.4095 & 0.4784 \\
\hline 21 & 21 & 22 & 1 & 0.7089 & 0.9373 \\
\hline 22 & 3 & 23 & 1 & 0.4512 & 0.3083 \\
\hline 23 & 23 & 24 & 1 & 0.8980 & 0.7091 \\
\hline 24 & 24 & 25 & 1 & 0.8960 & 0.7011 \\
\hline 25 & 6 & 26 & 1 & 0.2030 & 0.1034 \\
\hline 26 & 26 & 27 & 1 & 0.2842 & 0.1447 \\
\hline 27 & 27 & 28 & 1 & 1.0590 & 0.9337 \\
\hline 28 & 28 & 29 & 1 & 0.8042 & 0.7006 \\
\hline 29 & 29 & 30 & 1 & 0.5075 & 0.2585 \\
\hline 30 & 30 & 31 & 1 & 0.9744 & 0.9630 \\
\hline 31 & 31 & 32 & 1 & 0.3105 & 0.3619 \\
\hline 32 & 32 & 33 & 1 & 0.3410 & 0.5302 \\
\hline
\end{tabular}

\section{BIOGRAPHIES OF AUTHORS}

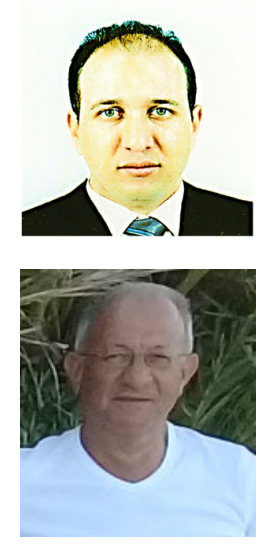

Abdelkader BOUAFIA received the B.Sc. degree in Electromechanical Engineering from the University of Skikda, Algeria, a M.S. degree from University of Annaba, He is currently a Ph.D. student at a laboratory of Electric Engineering, Department of Electrical Engineering. University Frères Mentouri-Constantine1(Algeria). His research activities are currently interesting on the future MV network, distributed generation, smart grid, network stability, and the impact of renewable energy on electrical power system. E-mail: bouafia.aek@gmail.com

Djamel LABED received the B.Sc. degree in Electrical Engineering from the University of Annaba, Algeria, the MSc. degree in Electrical Research Network from the Ecole Polytechnique of Montreal, Canada, and a PhD. degree in Electrical Engineering from the Mentouri University Constantine, Algeria.

In 1987, he joined Mentouri University Constantine, Algeria, has lecturer with the Department of Electrical Engineering, where he has been a Full Professor, and actually the Director of Electrical Engineering Laboratory Constantine LGEC.His research activities focus on: Impacts of Dispersed Generation; Various techniques for optimizing the optimal power flow; Identification of the weakest buses to facilitate the search for optimal placement of Var sources; Extreme learning machine based alleviation For overloaded power system; Stability of groups; Power flow method for DC networks integrated into AC; Analysis of different types of problem quality of electric power caused by renewable energy sources. E-mail: djamel_labed@yahoo.fr 